Research Article

\title{
Prevalence and Antimicrobial Susceptibility of Bacterial Uropathogens Isolated from Pediatric Patients at Yekatit 12 Hospital Medical College, Addis Ababa, Ethiopia
}

\author{
Yamirot Merga Duffa $\mathbb{D}^{1,2}$ Kumera Terfa Kitila ${ }^{1}{ }^{3},{ }^{3}$ Dereje Mamuye Gebretsadik $\left(\mathbb{D},{ }^{3}\right.$ \\ and Adane Bitew (D) $^{2}$ \\ ${ }^{1}$ Yekatit 12 Hospital Medical College, Departments of Microbiology, Addis Ababa, Ethiopia \\ ${ }^{2}$ Addis Ababa University, College of Health Sciences, Department of Medical Laboratory Sciences, Addis Ababa, Ethiopia \\ ${ }^{3}$ Ethiopia Public Health Institute (EPHI), Addis Ababa, Ethiopia
}

Correspondence should be addressed to Yamirot Merga Duffa; ymerga@gmail.com

Received 16 April 2018; Revised 27 June 2018; Accepted 9 July 2018; Published 2 October 2018

Academic Editor: Joseph Falkinham

Copyright (C) 2018 Yamirot Merga Duffa et al. This is an open access article distributed under the Creative Commons Attribution License, which permits unrestricted use, distribution, and reproduction in any medium, provided the original work is properly cited.

Background. Urinary tract infection (UTI) is considered as the most common bacterial infection seen among the pediatric patients. Objective. This study was carried out in order to determine the prevalence of urinary tract infection in pediatric patients, identify bacterial uropathogens responsible for the infection, and study the antibiotic sensitivity patterns of bacterial isolates. Materials and Methods. A cross-sectional study designed and conducted from January to April 2014. Clean-voided midstream urine specimens were obtained from 384 pediatric patients less than or equal to 15 years in sterile universal bottles. Urine collected from each patient was inoculated onto CLED and blood agar plates using a calibrated inoculating loop with a capacity of $0.001 \mathrm{ml}$. Inoculated plates were incubated for $24-48$ hours at $37^{\circ} \mathrm{C}$ at inverted position aerobically. Bacterial isolates were indentified and characterized by Gram stain and by using an array of standard routine biochemical tests. The antimicrobial susceptibility test was carried out by using the Kirby-Bauer disc diffusion method. Frequency distribution tables were used to describe the findings. Logistical regression was also used to estimate crude odds ratio (COR) with 95\% confidence interval (CI) of positive responses to the different variables, and $P$ values less than 0.05 were taken as statistically significant. Result. In this study, a total of 384 patients (199 males and 185 females) aged less than or equal to 15 years from whom urine samples were collected were enrolled. Of these patients, 61 (15.9\%) had significant bacteriuria. Of the 185 females, 36 (19.5\%) came up with positive cultures, while 25 (12.6\%) of the 199 males had significant bacteriuria, and the largest number of study subjects were below the age of 3 years, and the largest positive culture was obtained from this age group, accounting for $35(57.4 \%$.) out of 61 positive cultures. Bacterial species belonging to six genera were isolated and identified from 61 positive cultures, and the genera were Escherichia, Klebsiella, Staphylococcus, Proteus, Acinetobacter, and Enterococcus. E. coli was isolated in 28 cases (49.5\%), followed by Klebsiella spp. in 17 cases $(27.9 \%)$, Staphylococcus spp. in 5 patients (8.2\%.) (S. aureus in one and coagulase-negative staphylococci in 4 cases), Enterococcus in 7 cases (11.5\%), Proteus spp. in 3 cases (4.9\%), and Acinetobacter in one case (1.6\%). Of the bacterial isolates, E. coli was found out to be the most common pathogen followed by Klebsiella spp. Furthermore, E. coli and Klebsiella spp. were the most common pathogens in female patients accounting for $71.4 \%$ and $64.7 \%$, respectively. Regarding susceptibility tests, E. coli and Klebsiella spp. were not $100 \%$ susceptible to any of the 11 antibiotics tested. Acinetobacter spp. had $100 \%$ resistance to three antibiotics: gentamicin (GN), trimethoprim-sulfamethoxazole (SXM), and augmentin (AMP). But they were $100 \%$ susceptible to ciprofloxacin (CIP), cefuroxime (CXM), norfloxacin (NOR), and ceftazidime (CAZ). On the contrary, Proteus spp. was $100 \%$ sensitive to all drugs except to nitrofurantoin. Species of Enterococcus had resistance of $71.4 \%$ to chloramphenicol (C) and $85.7 \%$ to both SXM and erythromycin. S. aureus was 100\% susceptible to almost all drugs, while coagulase-negative staphylococci were not as susceptible as S. aureus. Multidrug resistance to two or more drugs was observed in $73.7 \%$ of the bacterial isolates. Conclusion. This study determined the prevalence of urinary tract infection in pediatric patients and highlighted the major bacterial uropathogens involved in UTI for the first time in the country. Furthermore, bacterial pathogen species and their frequency was consistent with the usually reported pattern, with E. coli being the most common organism isolated in cases of 
urinary tract infections followed by Klebsiella spp. Most of the bacterial isolates were multidrug resistant, and it is therefore suggested that appropriate antimicrobials should be administered to reduce the risk of multidrug resistant organisms developing and avert ineffectiveness of antibiotics. This condition indicates that antibiotic selection should be based on knowledge of the local prevalence of bacterial organisms and antibiotic sensitivities rather than empirical treatment. The present study indicated that ciprofloxacin (CIP), ceftazidime (CAZ), cefotaxime (CTX), cefuroxime (CXM), clindamycin (DA), and ceftriaxone (CRO) were the best antibiotics for the treatment of Gram-negative and Gram-positive bacterial uropathogens, respectively, in the study area relatively.

\section{Background}

Urinary tract infections (UTIs) are a common and important clinical problem in childhood and may lead to systemic illness and renal injury in the short term, and repeated infections, renal scarring, hypertension, and end-stage renal dysfunction may develop [1]. It is a serious health problem, and it has been estimated that about six million patients visit outpatient departments and about 300,000 are treated in the wards every year for UTI worldwide [2]. UTI is also a common and important clinical problem in pediatrics, as recurrent UTIs may lead to renal scarring, hypertension, and end-stage renal dysfunction later in life [3]. UTI occurs in $3 \%$ to $5 \%$ of girls and $1 \%$ of boys during childhood, with the first attack occurring in girls by 5 years, peaking during infancy and toilet training, while it is common in boys during the first year of life, especially among those who are uncircumcised [4]. UTI is caused mainly by bacteria, although viruses, fungi, and parasites can also cause urinary tract infections. Among bacteria, Gram-negative organisms are most commonly isolated from urine samples of children with Escherichia coli (E. coli) accounting for $70 \%$ to $90 \%$ of infections [5]. Klebsiella species, Proteus mirabilis, Pseudomonas aeruginosa, Acinetobacter, and Serratia are other Gram-negative bacteria isolated from pediatric patients. However, only $10 \%$ of the cases are caused by Gram-positive bacteria and include Enterococcus, Staphylococcus, and Streptococcus agalactiae [6].

In recent years, widespread use of antibiotics has resulted in an increasing incidence of antibiotic resistance among the urinary tract pathogens all over the world. Worldwide, emergence of antibiotic resistance is increasing among the urinary pathogens [7]. More than $80 \%$ of bacterial strains causing urinary tract infections in developing countries are now resistant to trimethoprim or trimethoprim-sulfamethoxazole [8].

Urinary tract infection (UTI) is one of the most common bacterial infections encountered by clinicians in developing countries and the cause of significant morbidity and mortality [9]. Several studies from the African continent have investigated the profile of common uropathogens and the pattern of their susceptibility to commonly used antimicrobial agents in order to guide the choice of empiric therapy. These studies reported the emergence of antibioticresistant Gram-negative bacilli with special emphasis on ESBL-producing isolates [10-12].

However, to the best of our knowledge, no such studies have been published describing the spectrum of uropathogens in pediatric patients and their antimicrobial susceptibility patterns in Ethiopia.
Therefore, this research was conducted with the aim of investigating the prevalence and patterns of antibiotic resistance of uropathogens among pediatric patients less than or equal to fifteen years at Yekatit 12 Teaching Medical Hospital, Addis Ababa, Ethiopia.

\section{Materials and Methods}

2.1. Study Area. The study was conducted at Yekatit 12 Hospital Medical College, which is located in the center of Addis Ababa. Yekatit 12 Teaching Hospital is one of the hospitals under Addis Ababa City Administration Health Bureau that has been giving routine health services for the city community and other referral cases from different regional states of Ethiopia. It is a tertiary level referral and teaching hospital in Addis Ababa that serves for a large number of people from the surrounding zones and nearby regions both for inpatient and outpatient treatment. This teaching hospital consists of an operating room, intensive care unit (ICU), and pediatric department with 12 beds, 13 wards with 327 beds, and outpatient departments.

2.2. Study Design and Period. It was a cross-sectional study designed and conducted with the objective of isolating, characterizing uropathogens in pediatric patients, and determining the antimicrobial susceptibility pattern of the isolates. The study was conducted prospectively from January to April 2014.

2.3. Source of Population. All pediatric patients not greater than 15 years of age attending Yekatit 12 Hospital Medical College were the source of population.

2.4. Study Population. All pediatric patients less than or equal to 15 years of age who were sent to the laboratory for urinalysis were included in the study.

2.5. Inclusion and Exclusion Criteria. Pediatric patients less than or equal to 15 years of age with urinalysis were included in the study, whereas pediatric patients who were taking antibiotics and mothers/guardians of pediatrics who did not volunteer for written consents were excluded.

2.6. Sample Size Determination and Sampling Technique. Since data were not available on pediatric bacterial UTI in Ethiopia, $50 \%$ of population proportion was used to determine the sample size based on single population 
proportion, and the level of precision (d) was 0.05. Urine specimens were collected from each pediatric patient. The study participants' parents or guardians were given appropriate instructions of clean catch midstream urine sample collection before providing urine samples, and immediately after collection, the samples were brought to microbiology laboratory for further process. Sterile plastic bags were used for admitted pediatric patients, and the bags were checked every 15 minutes for urine samples. Accordingly, about $10 \mathrm{ml}$ urine specimen was collected from each patient in a sterile screw-capped, wide-mouthed container labelled with unique sample numbers, date, and time of collection. Immediately, they were delivered to the bacteriology laboratory and processed.

The antimicrobial susceptibility test was carried out by the Kirby-Bauer disc diffusion method as per Clinical Laboratory Standards Institute (CLSI-formerly NCCLS) guidelines on Mueller-Hinton agar (Oxoid, Basingstoke, Hampshire, England [13]). Briefly, four to five bacterial colonies were inoculated into $5 \mathrm{ml}$ of Soyabean Casein Digest Broth (Oxoid, Basingstoke, Hampshire, England) and incubated at $37^{\circ} \mathrm{C}$ for 12 hours. After an overnight incubation, the growth suspension was prepared in $0.5 \mathrm{ml}$ of the same broth medium, and the turbidity was adjusted to match that of $0.5 \mathrm{McF}$ arland standards to obtain approximately the organism number of $1 \times 10^{6}$ colony-forming units (CFU) per ml. Then, a sterile swab was dipped into this suspension, and the excess of inocula was removed by pressing it against the sides of the tube. Then, the swab was applied to the center of Mueller-Hinton agar plate (Oxoid, Basingstoke, Hampshire, England) and evenly spread on the medium. Antibiotic discs were placed after 15 minutes of inoculation to Mueller-Hinton agar seeded with each isolate and were incubated for 24 hours at $37^{\circ} \mathrm{C}$. The diameter of the zone of inhibition around the disc was measured using a sliding metal caliper. Interpretation criteria were those of Clinical Laboratory Standards Institute (CLSI) guidelines. The following drugs and concentrations were used to determine the antibiogram of the strains: penicillin $(10 \mathrm{U})$, augmentin $(30 \mu \mathrm{g})$, trimethoprim-sulfamethoxazole $(1.25 / 23.75 \mu \mathrm{g})$, clindamycin $(30 \mu \mathrm{g})$, gentamicin $(30 \mu \mathrm{g})$, ciprofloxacin $(5 \mu \mathrm{g})$, erythromycin $(15 \mu \mathrm{g})$, chloramphenicol $(30 \mu \mathrm{g})$, cefuroxime $(30 \mu \mathrm{g})$, cephalothin $(10 \mu \mathrm{g})$, ceftazidime $(30 \mu \mathrm{g})$, cefotaxim $(30 \mu \mathrm{g})$, ceftriaxone $(10 \mu \mathrm{g})$, oxacillin $(1 \mu \mathrm{g})$, nitrofurantoin $(30 \mu \mathrm{g})$, nalidixic acid $(30 \mu \mathrm{g})$, and norfloxacin $(30 \mu \mathrm{g})$. All antibiotic disks were purchased from Oxoid Limited Company, United Kingdom.

2.7. Quality Control Assurance. The reliability of the study findings was guaranteed by implementing quality control measures throughout the whole process of the laboratory work. Staining reagents, culture media, and antibiotic discs were checked for their normal shelf life before use. All culture plates and antibiotic discs were stored at recommended refrigeration temperature $\left(2-8^{\circ} \mathrm{C}\right)$ after preparation. Reference strains of $S$. aureus ATCC 25923, E. coli ATCC 25922, and $P$. aeruginosa ATCC 27853 were used as controls. In general, all laboratory procedures were done based on recommended standard laboratory procedures by strictly following preanalytical, analytical, and postanalytical stages of quality assurance that are incorporated in standard operational procedures (SOPs) of microbiology laboratory of Yekatit 12 Hospital Medical College.

2.8. Data Analysis. Data were cleaned, entered, and analyzed using SPSS, version 17. Descriptive statistics was computed for most of the study variables, and frequency distribution tables were used to describe the findings. Logistical regression was also used to estimate crude odds ratio (COR) with $95 \%$ confidence interval (CI) of positive responses to the different variables, and $P$ values less than 0.05 were taken as statistically significant when looking for associations between dependent and independent variables.

\section{Results}

3.1. Sociodemographic Characteristics of Patients. There were 384 (199 males and 185 females) pediatric patients less than or equal to 15 years, from whom urine samples were collected. Of these patients, 61 (15.9\%) had significant bacteriuria. Of the 185 females, 36 (19.5\%) came up with positive cultures, while 25 (12.6\%) of the 199 males had significant bacteriuria, indicating that female patients were more affected than male patients. As can be seen in Table 1, the largest numbers of study subjects were below the age of 3 years, and the largest positive culture was obtained from this age group accounting for 35 (57.4\%.) positive cultures out of 61 positive cultures (Table 1 ).

Bacterial species belonging to six genera were isolated and identified from 61 positive cultures, and the genera were Escherichia, Klebsiella, Staphylococcus, Proteus, Acinetobacter, and Enterococcus; E. coli was isolated from 28 cases (49.5\%), followed by Klebsiella spp. from 17 cases (27.9\%), Staphylococcus spp. from 5 patients $(8.2 \%$.), S. aureus from one case and coagulase-negative staphylococci from 4 cases, Enterococcus from 7 cases (11.5\%), Proteus spp. from 3 cases (4.9\%), and Acinetobacter from one case (1.6\%). Of the bacterial isolates, E. coli was found to be the most common pathogen followed by Klebsiella. Furthermore, E. coli and Klebsiella were the most common pathogens in female patients accounting for $71.4 \%$ and $64.7 \%$, respectively (Table 2).

Isolation rate of UTI with regard to circumcision revealed that out of 178 circumcised male study subjects, $10.1 \%(18 / 178)$ were culture-positive, but from a total of 21 uncircumcised study subjects, $33.3 \%$ (7/21) were culturepositive. Circumcision was significantly associated (COR, 95\% CI: $0.225(0.080-0.630), P=0.005)$ with urinary tract infection (Table 3).

3.2. Antibiotic Sensitivity Testing. The drug susceptibility profile of bacterial isolates is given in Tables 4 and 5. E. coli and Klebsiella spp. were not $100 \%$ susceptible to any of the 11 antibiotics tested. On the one hand, Acinetobacter spp. had 100\% resistance to three antibiotics: gentamicin, trimethoprimsulfamethoxazole, and augmentin, but they were $100 \%$ 
TABLE 1: Distribution of bacterial isolates in relation to age group among pediatric patients at Yekatit 12 Hospital Medical College, Addis Ababa, Ethiopia, 2014.

\begin{tabular}{lccc}
\hline Age in years & Males with positive culture & Females with positive culture & Total \\
\hline$<3$ & $16(n=110)$ & $19(n=83)$ & 35 \\
$3-6$ & $1(n=13)$ & $3(n=20)$ & 4 \\
$6-9$ & $1(n=26)$ & $8(n=30)$ & 97.4 \\
$9-12$ & $2(n=24)$ & $4(n=29)$ & 6.6 \\
$12-15$ & $5(n=22)$ & $2(n=33)$ & 6 \\
Total & $25(40.9 \%)$ & $36(59.01 \%)$ & 7 \\
\hline
\end{tabular}

$n$ : number of patients in each age group; $N$ : total number of positive male and female patients in each age group.

TABLE 2: Distribution of bacterial isolates in relation to sex among pediatric patients at Yekatit 12 Hospital Medical College, Addis Ababa, Ethiopia, 2014.

\begin{tabular}{lccc}
\hline Bacterial isolates & Female & Male & Total \\
\hline E. coli & $20 / 28(71.4 \%)$ & $8 / 28(28.6)$ & $28 / 61(45.9 \%)$ \\
Klebsiella spp. & $11 / 17(64.7 \%)$ & $6 / 17(35.3)$ & $17 / 61(27.9 \%)$ \\
Proteus spp. & - & $3 / 3(100 \%)$ & $3 / 61(4.9 \%)$ \\
Acinetobacter spp. & - & $1 / 1(100 \%)$ & $1 / 61(1.6 \%)$ \\
Enterococcus spp. & $4 / 7(57.1)$ & $3 / 7(42.9 \%)$ & $7 / 61(11.5)$ \\
S. aureus & $1 / 1(100 \%)$ & - & $1 / 61(1.6 \%)$ \\
CONS & - & $4 / 4(100 \%)$ & $4 / 61(6.6 \%)$ \\
Total & $36(59.0)$ & $25(40.9 \%)$ & $61(100 \%)$ \\
\hline
\end{tabular}

CONS: coagulase-negative staphylococci.

TABLE 3: Association of UTI in relation to circumcision among pediatric patients at Yekatit 12 Hospital Medical College, Addis Ababa, Ethiopia, $2014(n=199)$.

\begin{tabular}{lcccc}
\hline Circumcision & No & Yes & COR 95\% CI & $\begin{array}{c}P \\
\text { value }\end{array}$ \\
\hline No & $14(66.6 \%)$ & $\begin{array}{c}7 \\
(33.3 \%)\end{array}$ & 1 & - \\
Yes & 160 & 18 & 0.225 & \\
& $(89.9 \%)$ & $(10.1 \%)$ & $(0.080-0.630)^{*}$ & 0.005 \\
\hline
\end{tabular}

* Significant at $P$ value $<0.05$; COR: crude odds ratio.

susceptible to ciprofloxacin, cefuroxime, norfloxacin, and ceftazidime. On the other hand, Proteus spp. were 100\% sensitive to all drugs except nitrofurantoin (Table 4).

Also, a high degree of resistance was observed in Enterococcus spp. Species of Enterococcus had resistance of 71.4 to chloramphenicol and $85.7 \%$ to both trimethoprimsulfamethoxazole and erythromycin (Table 5). As shown in Table 5, S. aureus was $100 \%$ susceptible to almost all drugs while coagulase-negative staphylococci were not as susceptible as $S$. aureus.

Multidrug resistance (MDR) to two or more drugs was observed in 11/12 (91.7\%) and 34/49 (69.4\%) of Gram-positive and Gram-negative bacteria, respectively, (Tables 6 and 7). The overall prevalence of MDR in both groups was 45/61 (73.7\%).

\section{Discussion}

The present study was conducted to determine the prevalence of UTIs, to evaluate the bacterial agents involved in UTI, and to determine the drug susceptibility profile of bacterial uropathogens. A total of 384 study participants were enrolled in the present study, of whom, $199(51.8 \%)$ were males and 185 (48.2\%) were females. The ages of study subjects ranged from 0 to 15 years.

Out of the 384 study subjects (185 female and 199 males between the ages of 0 and 15 years) who participated in this study, only $61(15.8 \%)$ had urine samples with significant bacteriuria. The findings of this study were similar to those reported in Nigeria [14], Iran [15], and Egypt [16], where prevalence rates of UTI documented were $11.96 \%, 16.2 \%$, and $15.05 \%$, respectively. However, the result obtained in this study (15.8\%) appeared to be higher when compared with those reported in Philadelphia [17], USA [6], India [18], and Nigeria [19]. The prevalence rates reported were $3.3 \%$, $7.0 \%, 4 \%$, and $3.0 \%$, respectively. On the contrary, the prevalence rate of UTI obtained in this study was much less than that reported by Olowu (1996), which was $28.1 \%$.

The present study revealed a higher incidence of urinary tract infection in females than in males. Of the 185 females, $36(36 / 185 ; 19.5 \%)$ came up with positive cultures, while 25 $(25 / 199 ; 12.6 \%)$ of the 199 males had significant bacteriuria indicating that female patients were more affected than male patients. Furthermore, the largest numbers of study subjects were patients below the age of 3 years. Among the culturepositive study subjects, $57.4 \%$ of them were below 3 years of age. Our result in this regard was comparable to that reported in Nigeria [14]. The higher incidence of urinary tract infections in females might be a result of shorter urethra and the proximity of their reproductive organ to the anus. UTI occurs in $3 \%$ to $5 \%$ of girls and $1 \%$ of boys during childhood, with the first attack occurring in girls by 5 years, peaking during infancy and toilet training, while it is common in boys during the first year of life, especially among those who are uncircumcised because during this time of age, they get exposed to pathogens easily $[15,18]$.

Sixty-one bacterial isolates were recovered from this study. They were E. coli, Klebsiella spp., Proteus spp., Enterococcus spp., Acinetobacter spp., S. aureus, and coagulasenegative staphylococci. Of these, $E$. coli was the most common organism isolated from patients with significant bacteriuria and was isolated from 28 (45.9\%) followed by Klebsiella spp. from 17 cases (27.9\%), Enterococcus spp from 7 cases $(11.5 \%)$, coagulase-negative staphylococci from 4 cases $(6.6 \%)$, Proteus spp. from 3 cases $(4.9 \%)$, and S. aureus from 1 case $(1.6 \%)$. The pattern and the frequency of bacterial isolates obtained in this study were comparable with different study findings done in different countries. For 
TABLE 4: The number and percent of resistant strains of Gram-negative uropathogens among pediatric patients at Yekatit 12 Hospital Medical College, Addis Ababa, Ethiopia, 2014.

\begin{tabular}{|c|c|c|c|c|c|c|c|c|c|c|c|c|}
\hline \multirow[b]{2}{*}{$\begin{array}{l}\text { Bacteria } \\
\text { isolated }\end{array}$} & \multirow[b]{2}{*}{$\begin{array}{c}\text { Total } \\
\text { no. }\end{array}$} & \multicolumn{11}{|c|}{ Antimicrobial agents tested } \\
\hline & & $\begin{array}{c}\text { CIP } \\
\text { No. }(\%)\end{array}$ & $\begin{array}{c}\text { CXM } \\
\text { No. (\%) }\end{array}$ & $\begin{array}{c}\text { GN } \\
\text { No. }(\%)\end{array}$ & $\begin{array}{c}\text { NA } \\
\text { No. }(\%) \\
\end{array}$ & $\begin{array}{c}\text { SXT } \\
\text { No. (\%) }\end{array}$ & $\begin{array}{c}\text { F } \\
\text { No. }(\%)\end{array}$ & $\begin{array}{c}\text { AMP } \\
\text { No. (\%) }\end{array}$ & $\begin{array}{c}\text { C } \\
\text { No. (\%) }\end{array}$ & $\begin{array}{c}\text { NOR } \\
\text { No. (\%) }\end{array}$ & $\begin{array}{c}\text { CTX } \\
\text { No. }(\%) \\
\end{array}$ & $\begin{array}{c}\text { CAZ } \\
\text { No. (\%) }\end{array}$ \\
\hline E. coli & 28 & $6(21.4)$ & $9(32.1)$ & $8(28.6)$ & $9(32.1)$ & $\begin{array}{c}19 \\
(67.9)\end{array}$ & $5(17.9)$ & $\begin{array}{c}11 \\
(39.3)\end{array}$ & $8(28.6)$ & $7(25.0)$ & $9(32.1)$ & $9(32.1)$ \\
\hline Klebsiella spp. & 17 & $5(29.4)$ & $\begin{array}{c}15 \\
(88.2)\end{array}$ & $\begin{array}{c}14 \\
(82.4)\end{array}$ & $9(52.9)$ & $\begin{array}{c}15 \\
(88.2)\end{array}$ & $5(29.4)$ & $\begin{array}{c}12 \\
(70.6)\end{array}$ & $\begin{array}{c}10 \\
(58.8)\end{array}$ & $6(35.3)$ & $\begin{array}{c}15 \\
(88.2)\end{array}$ & $\begin{array}{c}15 \\
(88.2)\end{array}$ \\
\hline $\begin{array}{l}\text { Acinetobacter } \\
\text { spp. }\end{array}$ & 1 & 0 & 0 & $1(100)$ & $1(100)$ & $1(100)$ & 0 & $1(100)$ & 0 & 0 & 0 & 0 \\
\hline Proteus spp. & 3 & 0 & 0 & 0 & 0 & 0 & $3(100)$ & 0 & 0 & 0 & 0 & 0 \\
\hline Total & 49 & $\begin{array}{c}11 \\
(22.5)\end{array}$ & $\begin{array}{c}24 \\
(48.9)\end{array}$ & $\begin{array}{c}23 \\
(46.9)\end{array}$ & $\begin{array}{c}19 \\
(38.7)\end{array}$ & $\begin{array}{c}35 \\
(71.4)\end{array}$ & $\begin{array}{c}13 \\
(26.5)\end{array}$ & $\begin{array}{c}24 \\
(48.9)\end{array}$ & $\begin{array}{c}18 \\
(36.7)\end{array}$ & $\begin{array}{c}13 \\
(26.5)\end{array}$ & $\begin{array}{c}24 \\
(48.9)\end{array}$ & $\begin{array}{c}24 \\
(48.9)\end{array}$ \\
\hline
\end{tabular}

AMP: augmentin $(30 \mu \mathrm{g})$; NOR: norfloxacin $(30 \mu \mathrm{g})$; GN: gentamicin $(30 \mu \mathrm{g})$; CIP: ciprofloxacin $(5 \mu \mathrm{g})$; NA: nalidixic acid $(30 \mu \mathrm{g})$; F: nitrofurantoin $(30 \mu \mathrm{g})$; CAZ: ceftazidime $(30 \mu \mathrm{g})$; CTX: cefotaxim $(30 \mu \mathrm{g})$; C: chloramphenicol $(30 \mu \mathrm{g})$; SXT: trimethoprim-sulfamethoxazole $(1.25 / 23.75 \mu \mathrm{g})$; CXM: cefuroxime $(30 \mu \mathrm{g})$.

TABLE 5: The number and percent of resistant strains of Gram-positive uropathogens among pediatric patients at Yekatit 12 Hospital Medical College, Addis Ababa, Ethiopia, 2014.

\begin{tabular}{|c|c|c|c|c|c|c|c|c|c|c|c|c|c|c|}
\hline \multirow[b]{2}{*}{$\begin{array}{l}\text { Bacteria } \\
\text { isolated }\end{array}$} & \multirow[b]{2}{*}{$\begin{array}{c}\text { Total } \\
\text { no. }\end{array}$} & \multicolumn{13}{|c|}{ Antimicrobial agents tested } \\
\hline & & $\begin{array}{c}\mathrm{P} \\
\text { No. } \\
(\%)\end{array}$ & $\begin{array}{l}\text { CIP } \\
\text { No. } \\
(\%)\end{array}$ & $\begin{array}{l}\text { C } \\
\text { No. } \\
(\%)\end{array}$ & $\begin{array}{c}\text { E } \\
\text { No. (\%) }\end{array}$ & $\begin{array}{l}\text { OX } \\
\text { No. } \\
(\%)\end{array}$ & $\begin{array}{l}\text { CXM } \\
\text { No. } \\
(\%)\end{array}$ & $\begin{array}{l}\text { GN } \\
\text { No. } \\
(\%)\end{array}$ & $\begin{array}{l}\text { KF } \\
\text { No. } \\
(\%)\end{array}$ & $\begin{array}{c}\text { SXT } \\
\text { No. (\%) }\end{array}$ & $\begin{array}{c}\text { F } \\
\text { No. } \\
(\%)\end{array}$ & $\begin{array}{l}\text { DA } \\
\text { No. } \\
(\%)\end{array}$ & $\begin{array}{l}\text { AMP } \\
\text { No. } \\
(\%)\end{array}$ & $\begin{array}{l}\text { CRO } \\
\text { No. } \\
(\%)\end{array}$ \\
\hline $\begin{array}{l}\text { Enterococcus } \\
\text { spp. }\end{array}$ & 7 & 0 & $\begin{array}{c}1 \\
(14.3)\end{array}$ & $\begin{array}{c}5 \\
(71.4)\end{array}$ & $6(85.7)$ & - & $\begin{array}{c}3 \\
(42.9)\end{array}$ & 0 & $\begin{array}{c}3 \\
(42.9)\end{array}$ & $6(85.7)$ & $\begin{array}{c}1 \\
(14.3)\end{array}$ & 0 & $\begin{array}{c}3 \\
(42.9)\end{array}$ & $\begin{array}{c}3 \\
(42.9)\end{array}$ \\
\hline CONS & 4 & 0 & $\begin{array}{c}1 \\
(25.0)\end{array}$ & $\begin{array}{c}1 \\
(25.0)\end{array}$ & $4(100)$ & - & $4(100)$ & 0 & 0 & $4(100)$ & 0 & 0 & $\begin{array}{c}1 \\
(25.0)\end{array}$ & $\begin{array}{c}1 \\
(25.0)\end{array}$ \\
\hline S. aureus & 1 & $1(100)$ & 0 & 0 & $1(100)$ & 0 & 0 & 0 & $1(100)$ & 0 & 0 & 0 & $1(100)$ & 0 \\
\hline Total & 12 & $1(8.3)$ & $\begin{array}{c}2 \\
(16.6)\end{array}$ & $6(50)$ & $\begin{array}{c}11 \\
(91.6)\end{array}$ & $\mathbf{0}$ & $\begin{array}{c}7 \\
(58.3)\end{array}$ & 0 & $\begin{array}{c}4 \\
(33.3)\end{array}$ & $\begin{array}{c}10 \\
(83.3)\end{array}$ & $1(8.3)$ & $\mathbf{0}$ & $\begin{array}{c}5 \\
(41.6)\end{array}$ & $\begin{array}{c}4 \\
(33.3)\end{array}$ \\
\hline
\end{tabular}

CONS: coagulase-negative staphylococci; P: penicillin (10 U); AMP: augmentin (30 $\mu \mathrm{g})$; KF: cephalothin (10 $\mu \mathrm{g})$; DA: clindamycin (30 $\mu \mathrm{g})$; CRO: ceftriaxone $(10 \mu \mathrm{g})$; GN: gentamicin $(30 \mu \mathrm{g})$; E: erythromycin $(15 \mu \mathrm{g})$; CIP: ciprofloxacin $(5 \mu \mathrm{g})$; OX: oxacillin (1 $\mu \mathrm{g}) ;$ F: nitrofurantoin $(30 \mu \mathrm{g})$; C: chloramphenicol $(30 \mu \mathrm{g})$; SXT: trimethoprim-sulfamethoxazole $(1.25 / 23.75 \mu \mathrm{g})$; CXM: cefuroxime $(30 \mu \mathrm{g})$.

TABLE 6: Multidrug resistance pattern of Gram-negative bacteria isolated from pediatric patients at Yekatit 12 Hospital Medical College, Addis Ababa, Ethiopia, 2014

\begin{tabular}{|c|c|c|c|c|}
\hline Combination of antibacterial agent & E. coli no. (\%) & Klebsiella spp. no. (\%) & Acinetobacter spp. no. (\%) & Total no. (\%) \\
\hline AMP, SXT & $3(16.6)$ & - & - & $3(8.8)$ \\
\hline C, SXT & $3(16.6)$ & - & - & $3(8.8)$ \\
\hline CIP, NOR, SXT & $1(5.6)$ & - & - & $1(2.94)$ \\
\hline AMP, SXT, NA, GN & $1(5.6)$ & - & $1(100)$ & $2(5.9)$ \\
\hline AMP, CIP, SXT, NOR, GN, CAZ, CTX, CXM & $4(22.2)$ & - & - & $4(11.8)$ \\
\hline AMP, SXT, NA, GN, CAZ, CTX, CXM, C & $4(22.2)$ & $4(26.7)$ & - & $8(23.5)$ \\
\hline CIP, SXT, NA, GN, CAZ, CTX, CXM, NOR, F & $1(5.6)$ & $5(33.3)$ & - & $6(17.6)$ \\
\hline AMP, SXT, NA, GN, CAZ, CTX, CXM, NOR, F & $1(5.6)$ & $6(40)$ & - & $7(20.6)$ \\
\hline Total & $18(100)$ & $15(100)$ & $1(100)$ & $34(100)$ \\
\hline
\end{tabular}

AMP: augmentin $(30 \mu \mathrm{g})$; NOR: norfloxacin $(30 \mu \mathrm{g})$; GN: gentamicin $(30 \mu \mathrm{g})$; CIP: ciprofloxacin $(5 \mu \mathrm{g})$; NA: nalidixic acid $(30 \mu \mathrm{g})$; F: nitrofurantoin $(30 \mu \mathrm{g})$; CAZ: ceftazidime $(30 \mu \mathrm{g})$; CTX: cefotaxim $(30 \mu \mathrm{g})$; C: chloramphenicol $(30 \mu \mathrm{g})$; SXT: trimethoprim-sulfamethoxazole $(1.25 / 23.75 \mu \mathrm{g})$; CXM: cefuroxime $(30 \mu \mathrm{g})$.

example, a study conducted in Iran [15] showed that, among bacterial isolates, $40 \%$ accounted for E. coli, and this was followed by Klebsiella spp. (17.9\%), coagulase-negative staphylococci (12.3\%), Enterococcus spp. (8.7\%), Pseudomonas spp. (6.7\%), and S. aureus (3.6\%). A study conducted in Nigeria [14] reported a total of 36 bacterial isolates, of which, E. coli was the predominant organism and was responsible for $52.77 \%$ of the cases of UTI, and this was followed by Klebsiella spp. (25\%), Proteus mirabilis (13.89\%), Streptococcus faecalis (5.56\%), and Pseudomonas aeruginosa (2.78\%). Similarly, a study conducted in Egypt [16] indicated that, among all the bacteria isolated in their study, E. coli and Klebsiella spp. were the most commonly isolated bacteria accounting for $58.1 \%$ and $41.9 \%$, respectively This study was 
TABle 7: Multidrug resistance pattern of Gram-positive bacteria isolated from pediatric patients at Yekatit 12 Hospital Medical College, Addis Ababa, Ethiopia, 2014.

\begin{tabular}{|c|c|c|c|c|}
\hline Combination of antibacterial agent & Enterococcus spp. no. (\%) & S. aureus no. (\%) & CONS no. (\%) & Total no. (\%) \\
\hline $\mathrm{P}, \mathrm{AMP}, \mathrm{KF}$ & - & $1(100)$ & - & $1(9.09)$ \\
\hline P, SXT, E, CXM & - & - & $3(75)$ & $3(27.2)$ \\
\hline $\mathrm{P}, \mathrm{SXT}, \mathrm{E}, \mathrm{C}$ & $2(33.3)$ & - & - & $2(18.2)$ \\
\hline P, SXT, E, C, AMP & $1(16.7)$ & - & $1(25)$ & $2(18.2)$ \\
\hline CXM, E, F, AMP, SXT & $1(16.7)$ & - & - & $1(9.09)$ \\
\hline CXM, E, F, KF, CRO, SXT, C & $1(16.7)$ & - & - & $1(9.09)$ \\
\hline C, E, F, KF, CRO, SXT & $1(16.7)$ & - & - & $1(9.09)$ \\
\hline Total & $6(100)$ & $1(100)$ & $4(100)$ & $11(100)$ \\
\hline
\end{tabular}

CONS: coagulase-negative staphylococci; P: penicillin (10 U); AMP: augmentin (30 $\mu \mathrm{g})$; KF: cephalothin (10 $\mu \mathrm{g})$; DA: clindamycin (30 $\mu \mathrm{g})$; CRO: ceftriaxone $(10 \mu \mathrm{g})$; GN: gentamicin $(30 \mu \mathrm{g})$; E: erythromycin $(15 \mu \mathrm{g})$; CIP: ciprofloxacin $(5 \mu \mathrm{g})$; OX: oxacillin $(1 \mu \mathrm{g})$; F: nitrofurantoin $(30 \mu \mathrm{g})$; C: chloramphenicol $(30 \mu \mathrm{g})$; SXT: trimethoprim-sulfamethoxazole $(1.25 / 23.75 \mu \mathrm{g})$; CXM: cefuroxime $(30 \mu \mathrm{g})$.

comparable with the study conducted in different areas $[20,24,26]$.

A study conducted in Philadelphia [17] indicated uncircumcision as one of the risk factors for UTI; a study in USA [6] also showed that the prevalence of UTI was less in circumcised males $(2.4 \%)$ than in uncircumcised males (20.1\%). This study has also showed that circumcised $(10.1 \%)$ male patients were less susceptible to bacterial pathogens than were uncircumcised $(33.3 \%)$ patients.

The drug susceptibility profile of Gram-negative and Gram-positive bacteria tested in the present study was variable. For instance, E. coli and Klebsiella spp. were not $100 \%$ susceptible to any of the 11 antibiotics tested. However, percentage resistance of Klebsiella was much higher when compared with that of E. coli. Eighty-eight percent of Klebsiella spp. was resistant to cefotaxim, ceftazidime, trimethoprim-sulfamethoxazole, and cefuroxime. The drug susceptibility profile of E. coli and Klebsiella spp. obtained in the present study was similar with the findings in Ilorin [20]. However, drug susceptibility profile of E. coli in this study strongly contradicts with the findings reported in Tanzania [21]. On the one hand, Acinetobacter spp. had 100\% resistance to four antibiotics: gentamicin, trimethoprimsulfamethoxazole, augmentin, and nalidixic acid and $100 \%$ susceptible to ciprofloxacin, cefuroxime, norfloxacin, cefotaxim, chloramphenicol, and ceftazidime. The present finding with regard to these isolated pathogens strongly contradicted with the findings in Iran [15]. On the other hand, Proteus spp. was $100 \%$ sensitive to all drugs except nitrofurantoin. Also, a high degree of resistance was observed in Enterococcus spp. Enterococcus spp. were 100\% sensitive to penicillin but were resistant to chloramphenicol by $71.4 \%$ and by $85.7 \%$ to both trimethoprimsulfamethoxazole and erythromycin. Similarly, S. aureus was $100 \%$ susceptible to almost all drugs, while coagulasenegative staphylococci were not as susceptible as $S$. aureus. This study also showed that both Gram-positive and Gramnegative bacteria had multidrug resistance (MDR) to two or more drugs with an overall prevalence of $45 / 61$ (73.7\%) in both groups. This finding was also supported by different study findings conducted in different areas [27-30]. Finally, as a limitation, the lack of such similar studies in Ethiopia for the purposes of comparison and absence of some biochemical reagents and antibiotic discs might influence the appreciation of complete profile of isolates. Serotyping and genotyping of bacterial isolates especially multidrugresistant organisms were not possible due to limited laboratory facility.

\section{Conclusion and Recommendation}

This study determined the prevalence of urinary tract infection in pediatric patients and highlighted the major bacterial uropathogens involved in UTI for the first time in the country. Furthermore, bacterial pathogen species and their frequency was consistent with the usually reported pattern, with $E$. coli being the most common organism isolated in cases of urinary tract infections followed by Klebsiella spp. Most of the bacterial isolates were multidrug resistant, and it is therefore suggested that appropriate antimicrobials should be administered to reduce the risk of multidrug-resistant organisms developing and avert ineffectiveness of antibiotics. A widespread screening program for UTI in pediatric should be implemented to know the exact prevalence and to measure resistance rate of uropathogens to commonly used antibiotics.

Finally, the authors recommended that treatments of bacterial uropathogens indicate that antibiotic selection should be based on knowledge of the local prevalence of bacterial organisms and antibiotic sensitivities rather than empirical treatment. The present study indicated that ciprofloxacin (CIP), ceftazidime (CAZ), cefotaxime (CTX), cefuroxime (CXM), clindamycin (DA), and ceftriaxone (CRO) were the best antibiotic treatment against Gramnegative and Gram-positive bacterial uropathogens, respectively, in the study area relatively.

\section{Abbreviations}

AST: Antimicrobial susceptibility testing

BA: Blood agar

CLED: Cystine-lactose-electrolyte deficient

CI: Confidence interval

CONS: Coagulase-negative staphylococci

CLSI: Clinical Laboratory Standards Institute

DMLT: Department of Medical Laboratory Technology

ESBL: $\quad$ Extended-spectrum $\beta$-lactamase

KIA: Kligler iron agar 
IRB: Institutional Review Board

MSU: Midstream urine samples

NCCLS: National Committee for Clinical Laboratory

Standards

OPD: Outpatient Department

QC: Quality control

SOPs: Standard operating procedures

Spp: $\quad$ Species

SPSS: $\quad$ Statistical Package for Social Sciences

UTI: Urinary tract infection

USA: United States of America

WHO: World Health Organization.

\section{Data Availability}

The data used to support the findings of this study cannot be shared in a publicly available data repository system, because there is no such a data repository system in the country. However, the data are available form the authors upon request.

\section{Ethical Approval}

The study was conducted after it was ethically reviewed and approved by the Institutional Review Board (IRB) of Department of Medical Laboratory Sciences, College of Health Sciences, Addis Ababa University. Ethical clearance was also obtained from Addis Ababa Health Bureau. Then, a letter informing the hospital was written from the health bureau, and permission was obtained from Yekatit 12 Hospital.

\section{Consent}

Informed written consents were obtained from mothers/guardians of pediatric patients before data collection. The respondent was given the right to refuse to take part in the study as well as to withdraw at any time during the study period. All the information obtained from the study subjects was coded to maintain confidentially. When the participants are found to be positive for urine culture, they were informed by the hospital clinician and received proper treatment.

\section{Conflicts of Interest}

The authors declare that they have no conflicts of interest.

\section{Authors' Contributions}

YMD conceived and designed the study protocol, collected data, performed analysis, and interpreted data. All of the authors critically reviewed and approved the manuscript.

\section{Acknowledgments}

The authors would like to acknowledge Addis Ababa University, School of Medical Laboratory Sciences, for creating and facilitating this research work opportunity. The authors express their heartfelt thanks to the study participants for their willingness and being involved in this study. Lastly, the authors also acknowledge staff members of the hospitals that helped them in data collection, preparation, and laboratory examination activities.

\section{References}

[1] B. Mathur, H. S. Agarwal, and A. Maria, "Acute renal failure in neonatal sepsis," Indian Journal of Pediatrics, vol. 73, no. 6, pp. 499-502, 2006.

[2] E. Akortha and K. Ibadin, "Incidence and antibiotic susceptibility pattern of Staphylococcus aureus among patients with urinary tract infection in UBTH Benin City, Nigeria," African Journal of Biotechnology, vol. 7, no. 11, pp. 1637-1640, 2008.

[3] J. Joseph, A. Darcie, and N. Kiddoo, "Diagnosis and management of pediatric urinary tract infections," Clinical Microbiology Reviews, vol. 18, no. 2, pp. 417-422, 2005.

[4] J. A. Owa, J. C. Azubuike, and K. E. Nkangineme, "Urinary tract infections in children," in Paediatrics and Child Health in a Tropical Region, pp. 480-481, African Educational Services, Owerri, Nigeria, 1999.

[5] R. E. Behrman, R. M. Kliegman, and H. B. Jenson, "Urinary tract infection," in Nelson Textbook of Pediatrics, vol. 17, pp. 1621-1625, Elsevier, Philadelphia, PA, USA, 2004.

[6] N. Shaikh, N. E. Morone, J. E. Bost, and M. H. Farrell, "Prevalence of urinary tract infection in childhood: a metaanalysis," Pediatric Infectious Disease Journal, vol. 27, no. 4, pp. 302-308, 2008.

[7] R. Runehagen and G. Kahlmeter, "A 10- year study of the consumption of quinolones trimethoprim and mecillinam in relation to the development of antimicrobial resistance in a large number of species," in Proceeding of European Congress of Clinical Microbiology and Infectious Diseases, Poster 417, Amsterdam, Netherlands, July 2002.

[8] G. Kahlmeter, "An international survey of the antimicrobial susceptibility of pathogens from uncomplicated urinary tract infections: the ECO-SENS project," Journal of Antimicrobial Chemotherapy, vol. 51, no. 1, pp. 69-76, 2003.

[9] B. Tessema, A. Kassu, A. Mulu, and G. Yismaw, "Predominant isolates of urinary tract pathogens and their antimicrobial susceptibility in Gondar University Teaching Hospital, northwest Ethiopia," Ethiopian Medical Journal, vol. 45, no. 1, pp. 61-67, 2007.

[10] O. A. Aboderin, A. R. Abdu, B. W. Odetoyin, and A. Lamikanra, "Antimicrobial resistance in Escherichia coli strains from urinary tract infections," Journal of the National Medical Association, vol. 101, no. 12, pp. 1268-1273, 2009.

[11] R. Bercion, D. Mossoro-Kpinde, A. Manirakiza, and A. L. Faou, "Increasing prevalence of antimicrobial resistance among Enterobacteriaceae uropathogens in Bangui, Central African Republic," Journal of Infection in Developing Countries, vol. 3, no. 3, pp. 187-190, 2009.

[12] T. M. Habte, S. Dube, N. Ismail, and A. A. Hoosen, "Hospital and community isolates of uropathogens at a tertiary hospital in South Africa," South African Medical Journal, vol. 99, no. 8, pp. 584-588, 2009.

[13] Clinical Laboratory Standards Institute, 2009 Guidelines by CLSI/NCCLS Information Supplement, Approved Standard M 100-S15, Wayne, PA, USA, 2000..

[14] O. A. Aiyegoro, O. O. Igbinosa, I. N. Ogunmwonyi et al., "Incidence of urinary tract infections (UTI) among children and adolescents in Ile-Ife, Nigeria," African Journal of Microbiology Research, pp. 13-19, 2007. 
[15] R. Ranjbar, M. T. Haghi-Ashtiani, N. Jonaidi Jafari, and M. Abedini, "The prevalence and antimicrobial susceptibility of bacterial uropathogens isolated from pediatric patients," Iranian Journal of Public Health, vol. 38, no. 2, pp. 134-213, 2009.

[16] D. M. Yousssef, H. A. Elfateh, R. Sedeck, and S. Seleem, "Epidemiology of urinary tract infection in neonatal intensive care unit: a single center study in Egypt," Journal of Academy of Medical Sciences, vol. 2, no. 1, pp. 25-29, 2012.

[17] K. N. Shaw, M. Gorelick, K. L. McGowan, N. M. Yakscoe, and J. S. Schwartz, "Prevalence of urinary tract infection in febrile young children in the emergency department," Pediatrics, vol. 102, no. 2, p. e16, 1998.

[18] C. Ashok, G. V. Kumar, and H. M. Viswanathakumar, "Study of the prevalence and clinical profile of urinary tract infection in febrile children aged 3-6 years who attended pediatric outpatient department in a tertiary care hospital," International Journal of Health Sciences and Research, vol. 3, no. 2, pp. 1-5, 2013.

[19] V. U. Muoneke, M. U. Ibekwe, and R. C. Ibekwe, "Childhood urinary tract infection in Abakaliki: etiological organisms and antibiotic sensitivity pattern," Annals of Medical and Health Sciences Research, vol. 2, no. 1, pp. 29-32, 2012.

[20] O. T. Adedoyin, B. O. Oyeymi, and O. V. Aiyedehin, "Screening of febrile children on hospital admission for urinary tract infections (UTI)," African Journal of Clinical and Experimental Microbiology, vol. 4, no. 1, pp. 56-62, 2003.

[21] B. P. Msaki, E. Stephen, S. E. Mshana, A. Hokororo, H. D. Mazigo, and M. D. Domenica, "Prevalence and predictors of urinary tract infection and severe malaria among febrile children attending Makongoro health centre in Mwanza city, North-Western Tanzania," Archives of Public Health, vol. 70, no. 1, pp. 1-8, 2012.

[22] S. K. Abdulhadi, A. H. Yashua, and A. Uba, "Organisms causing urinary tract infection in paediatric patients at Murtala Muhammad Specialist Hospital, Kano, Nigeria," Journal of Internal of Biomedical and Health Science, vol. 4, no. 4, pp. 165-167, 2008.

[23] B. Fantahun and A. Bayeh, "Antimicrobial resistance of bacterial isolates from urinary tract infections at Felge Hiwot Referral Hospital, Ethiopia," Ethiopian Journal of Health Development, vol. 23, no. 3, pp. 236-238, 2009.

[24] G. Beyene and T. W. Wondewosen, "Bacterial uropathogens in urinary tract infection and antibiotic susceptibility pattern in Jimma University Specialized Hospital, Southwest Ethiopia," Ethiopian Journal of Health Sciences, vol. 21, no. 2, pp. 141-146, 2011.

[25] A. Hoberman, H. P. Chao, D. M. Keller, R. Hickey, H. W. Davis, and D. Ellis, "Prevalence of urinary tract infection in febrile infants," Journal of Pediatrics, vol. 123, no. 1, pp. 17-23, 1993.

[26] C. W. Lin, Y. H. Chiou, Y. Y. Chen et al., "Urinary tract infection in neonates," Journal of Clinical Neuroscience, vol. 6, no. 2, pp. 1-4, 1999.

[27] E. J. Schoen, C. J. Colby, and G. T. Ray, "Newborn circumcision decreases incidence and costs of urinary tract infections during the first year of life," Pediatrics, vol. 105, no. 4, pp. 789-793, 2000.

[28] M. Barton, Y. Bell, M. Thame, A. Nicholson, and H. Trotman, "Urinary tract infection in neonates with serious bacterial infections admitted to the university hospital of the West Indies," West Indian Medical Journal, vol. 57, no. 2, pp. 101-105, 2008.

[29] B. T. Van der Meeren, K. D. Chhaganlal, A. Pfeiffer et al., "Extremely high prevalence of multi-resistance among uropathogens from hospitalised children in Beira, Mozambique," South African Medical Journal, vol. 103, no. 6, pp. 382-386, 2013.

[30] W. A. Olowu, "Symptomatic bacteriuria in children, Nigeria," African Journal of Microbiology Research, vol. 27, pp. 76-80, 1996. 


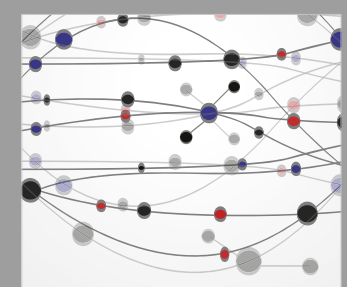

The Scientific World Journal
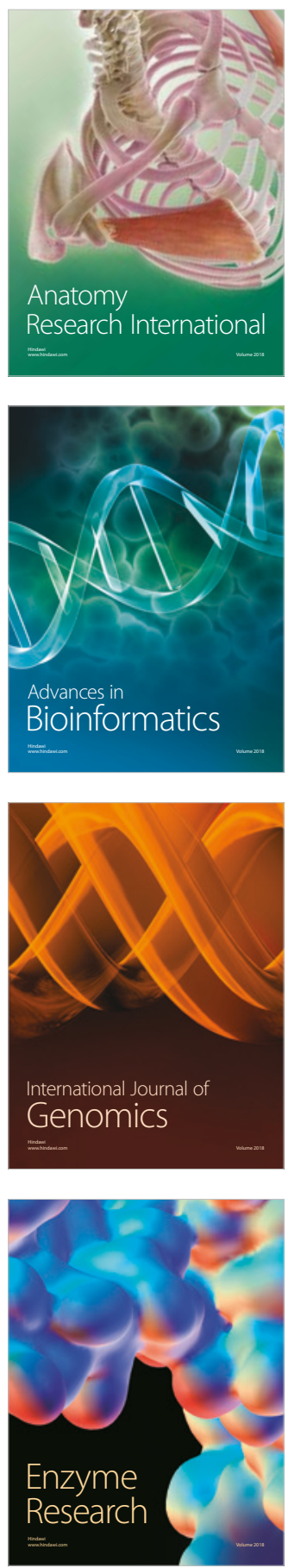
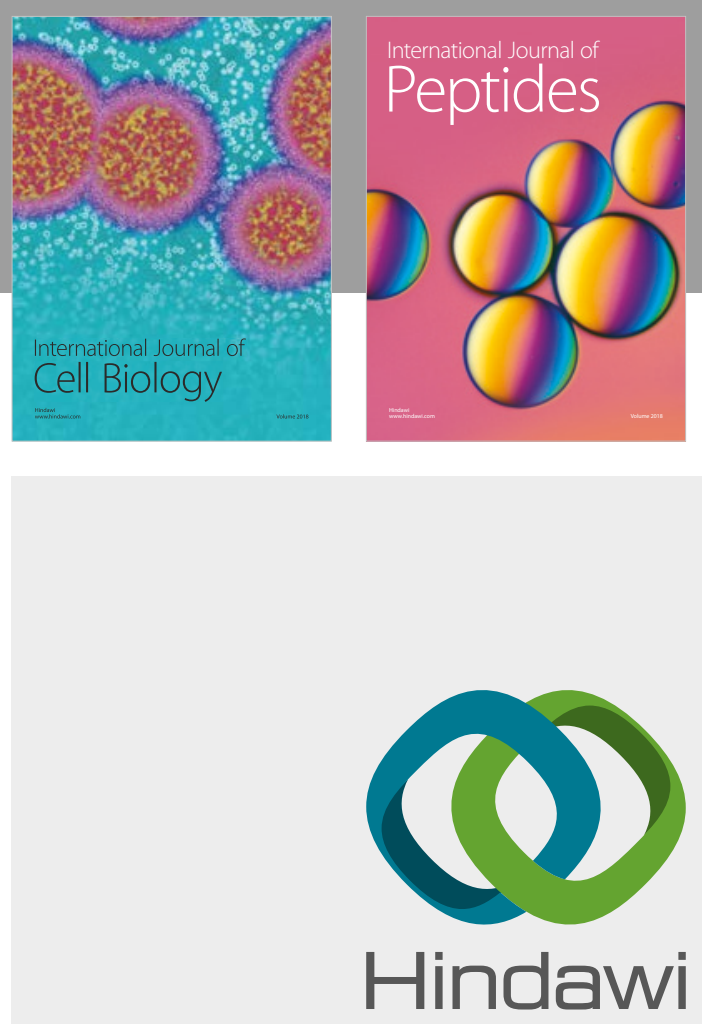

Submit your manuscripts at

www.hindawi.com
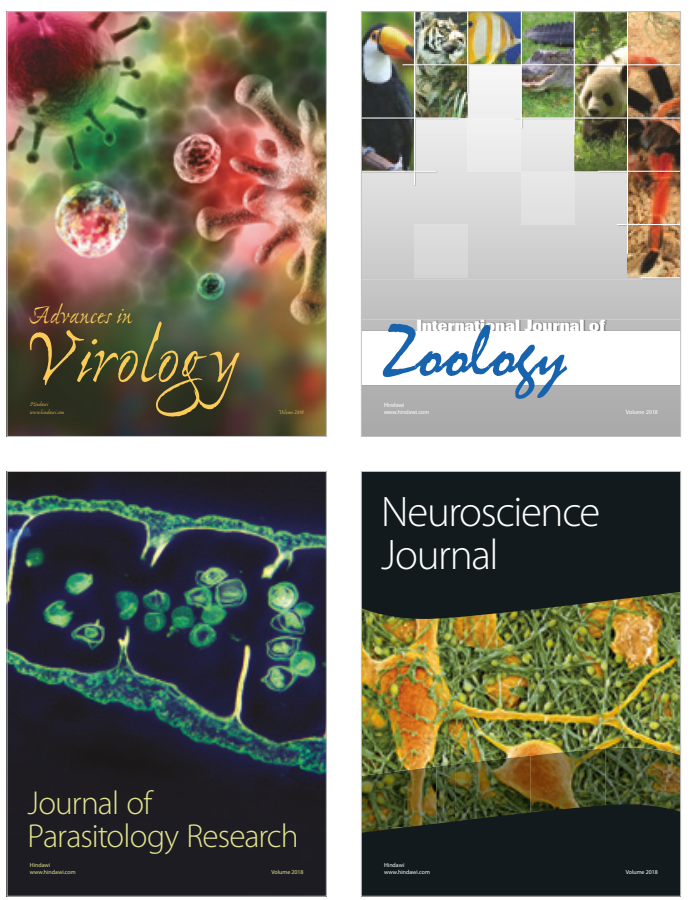
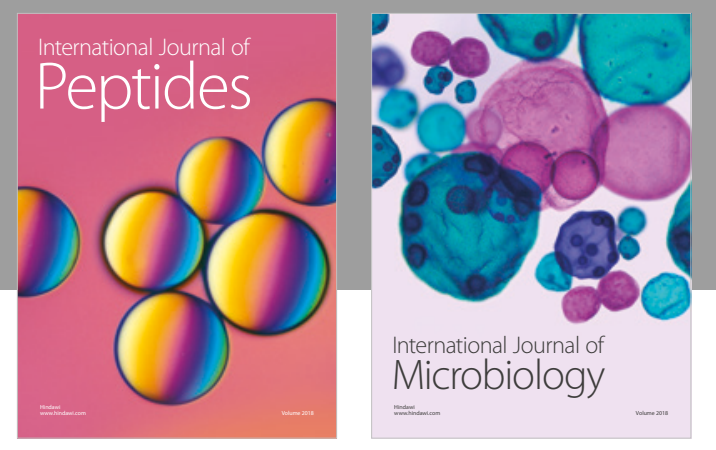

nternational Journal of Microbiology
Journal of
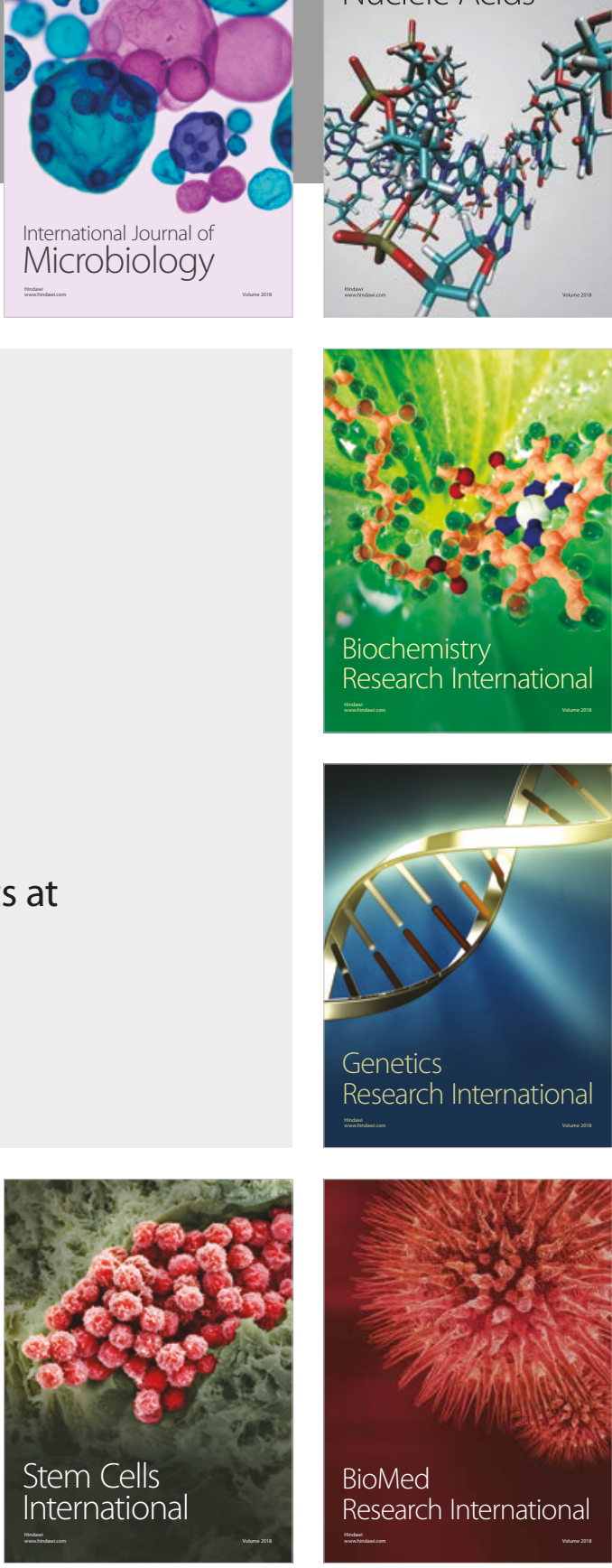
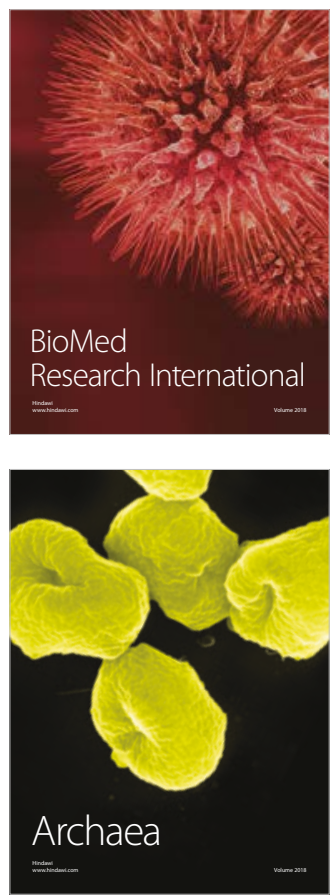